\title{
Skin Regeneration Symposium Cambridge, 12-13 April 2016
}

The Annual Skin Regeneration Symposium, held in Cambridge, UK, 12-13 April 2016, explored the latest advancements in skin repair, regeneration and restoration, and the impact this has on patients. With over 140 delegates from the disciplines of burn and trauma care, chronic wounds and esthetic medicine, the symposium sparked lively debate and the sharing of results from interesting case studies, clinical trials and basic research to support the use of a Regenerative Epithelial Suspension produced using the ReCell ${ }^{\circledR}$ technology. Furthermore, it enabled delegates and speakers alike to share ideas and discuss how to improve the quality of care for patients.

First draft submitted: 23 May 2016; Accepted for publication: 25 May 2016; Published online: 30 June 2016

Keywords: burns $\bullet$ esthetic medicine $\bullet$ skin regeneration $\bullet$ tissue viability $\bullet$ wound healing

Regenerative epithelial suspension (RES) features all the epithelial elements needed to support the healing cascade, leading to the restoration of normal healthy skin [1]. It is an autologous preparation produced using the $\mathrm{ReCell}^{\circledR}$, ReNovaCell ${ }^{\mathrm{TM}}$ or ReGenerCell ${ }^{\mathrm{TM}}$ medical device at point of care using a sample of the patient's own skin.

The innovator behind RES technology, Professor Fiona Wood (Fiona Stanley Hospital and Princess Margaret Hospital for Children, Australia), welcomed delegates to the symposium with opening remarks on the importance of regenerative medicine, the body's healing responses and the role of cell-based technologies in epidermal and dermal repair. Use of RES has been incorporated into routine clinical practice as an adjunct to standard care, but there are still barriers to implementation that remain to be understood, as well as how cell-based therapies can influence effective skin regeneration going forward.

Skin is highly regenerative, but when breached it can cause significant pathologies beyond that of the original site of injury and may lead to harm to the person as a whole. It is therefore time to raise the bar in treatment - beyond what is perceived as the 'gold standard'. Research has found that the impact of a burn injury can in turn impact on the patient's life trajectory as a whole even if they survive [2]. Restoration of good quality skin plays a significant role in this outcome. Scarring itself is an abnormal construct, and the impact of the altered skin structure on other body systems, including immune response, is an area of research in its infancy. However, what is known is that regeneration rather than scar formation is key; how healing can be improved to reduce this impact must be explored. Use of an autologous skin cell suspension containing all the cell types found in normal skin is an important part of regeneration. Driving the technology forward, building on previous success and sharing experiences is essential for the outcomes and quality of life (QoL) of the patients we treat.

\section{Transforming lives: the use of ReCell ${ }^{\circledR}$ in the Taiwan Waterpark Mass Casualty event}

In the opening lecture, Hung-Hui Liu (Taiwan Tri-Service General Hospital, Taiwan) shared the successful experience of using the
Rosalind Hill

Future Science Group, London UK Tel: +44 2083716090

r.hill@future-science-group.com 
RES produced using the $\mathrm{ReCell}{ }^{\circledR}$ technology in burn patients following the 27 June 2015 Formosa Water Park explosion. Out of the 500 people injured, more than half had a greater than $40 \%$ total burn surface area (TBSA), and 22 a greater than $80 \%$ TBSA. The Taiwan Tri-Service General Hospital admitted 61 injured patients. Out of these, 31 had greater than $40 \%$ TBSA and four a greater than $80 \%$ TBSA. All of these patients were treated successfully and survived. A crisis management protocol was implemented and a plastic surgery ward was converted into a dedicated burns center with a large multidisciplinary team. This team met every morning to discuss patient conditions and agree treatment plans.

The Tri-Service team initiated twice daily dressing changes and a modified Parkland fluid resuscitation protocol based on Jeffrey Saffle's 2009 burn protocol $[3,4]$ monitoring cardiac index $(\mathrm{CI})$ and stroke volume variation (SVV) were monitored using $\mathrm{FloTrac}^{\circledast} /$ Vigileo $^{\circledR}$ (Edwards Lifesciences) to optimize outcomes. Patients with a greater than or equal to $12 \%$ SVV were placed on fluids and CI was maintained at 2.5 ; if less than $12 \% \mathrm{SVV}$, urine output was monitored. The team adjusted the intravenous rate based on each patient's urine output. This was repeated hourly. Ten patients were placed on this protocol, with an average TBSA of $61.5 \%$, all of whom were mechanically ventilated and sedated. Compared with the traditional Parkland formula, the team had completed fluid resuscitation within the first $32 \mathrm{~h}$. In the first $24 \mathrm{~h}$, the amount of fluid was $4.1 \mathrm{ml} / \mathrm{kg}$, which decreased to $2.0 \mathrm{ml} / \mathrm{kg}$ burn TBSA over the next $24 \mathrm{~h}$. There was no sustained shock among patients beyond $48 \mathrm{~h}$.

Early and aggressive interventions were key to success. All patients received escharotomy and no patients required amputation. Early debridement and skin grafting was carried out, but as all patients had severe burns, there was a limit to the number of donor sites available. However, Taiwan Tri-Service General Hospital stores cadaveric skin, and was able to make use of cell suspensions in combination with meshed skin grafts to reduce the amount of donor skin required. This was produced using $\mathrm{ReCell}^{\circledR}$ in six patients with an average burn TBSA of $65 \%$ (Table 1).

Due to limitations in availability of the $\mathrm{ReCell}^{\circledR}$ device at the time, RES was applied on alternate sides. By doing so the team was able to demonstrate some very obvious differences in treatment outcome. Sites treated with RES displayed faster epithelization, particularly when combined with VAC (Figure 1). During followup, minimal scarring and contracture of the REStreated areas were observed by clinician and patient.

Table 1. Case examples from Taiwan Tri-Service General Hospital.

\begin{tabular}{|c|c|c|c|c|c|}
\hline Case number & Age (years) & Gender & TBSA (\%) & Area & Treatment method \\
\hline 1 & 27 & M & 80 & $\begin{array}{l}\text { Bilateral lower } \\
\text { leg } \\
\text { Trunk } \\
\text { Left upper arm }\end{array}$ & $\begin{array}{l}\text { MEEK }(1: 6)+\operatorname{ReCell}^{\circledast} \text { (failed owing to } \\
\text { sepsis infection) } \\
\text { Mesh }(1: 3)+\operatorname{ReCell}^{\circledast} \\
\text { Mesh }(1: 3)+\operatorname{ReCell}^{\circledast}\end{array}$ \\
\hline 2 & 19 & $\mathrm{~F}$ & 55 & $\begin{array}{l}\text { Left upper and } \\
\text { lower limbs }\end{array}$ & Mesh $(1: 1.5)+$ ReCell ${ }^{\circledast}$ \\
\hline 3 & 22 & M & 55 & $\begin{array}{l}\text { Right upper } \\
\text { arm, forearm } \\
\text { and left hand } \\
\text { Bilateral lower } \\
\text { legs }\end{array}$ & $\begin{array}{l}\text { Mesh }(1: 1.5)+\text { ReCell}^{\circledR}\left(\text { ReCell}^{\circledR} \text { not }\right. \\
\text { used immediately, but only after } \\
\text { poor healing noticed in right arm; } \\
\text { after } 1 \text { week with ReCell }{ }^{\circledR} \text { healing } \\
\text { was almost complete. } \text { ReCell }^{\circledR} \text { then } \\
\text { used over hand and forearm - after } \\
4 \text { weeks excellent healing was seen. } \\
\text { On bilateral leg healing was almost } \\
\text { completed after } 2 \text { weeks. } 4 \text { weeks } \\
\text { post-treatment scarring was minimal) }\end{array}$ \\
\hline 4 & 21 & M & 60 & Left lower leg & $\begin{array}{l}\text { MEEK }(1: 4)+\operatorname{ReCell}^{\circledR}+\mathrm{VAC} \text { (results } \\
\text { shown in Figure 1) }\end{array}$ \\
\hline 5 & 26 & M & 80 & $\begin{array}{l}\text { Trunk } \\
\text { Right foot }\end{array}$ & $\operatorname{MEEK}(1: 4)+\operatorname{ReCell}^{\circledR}+\mathrm{VAC}$ \\
\hline 6 & 23 & M & 60 & $\begin{array}{l}\text { Right upper } \\
\text { limb } \\
\text { Right lower leg }\end{array}$ & MEEK (1:4) + ReCell ${ }^{\oplus}+$ VAC \\
\hline
\end{tabular}




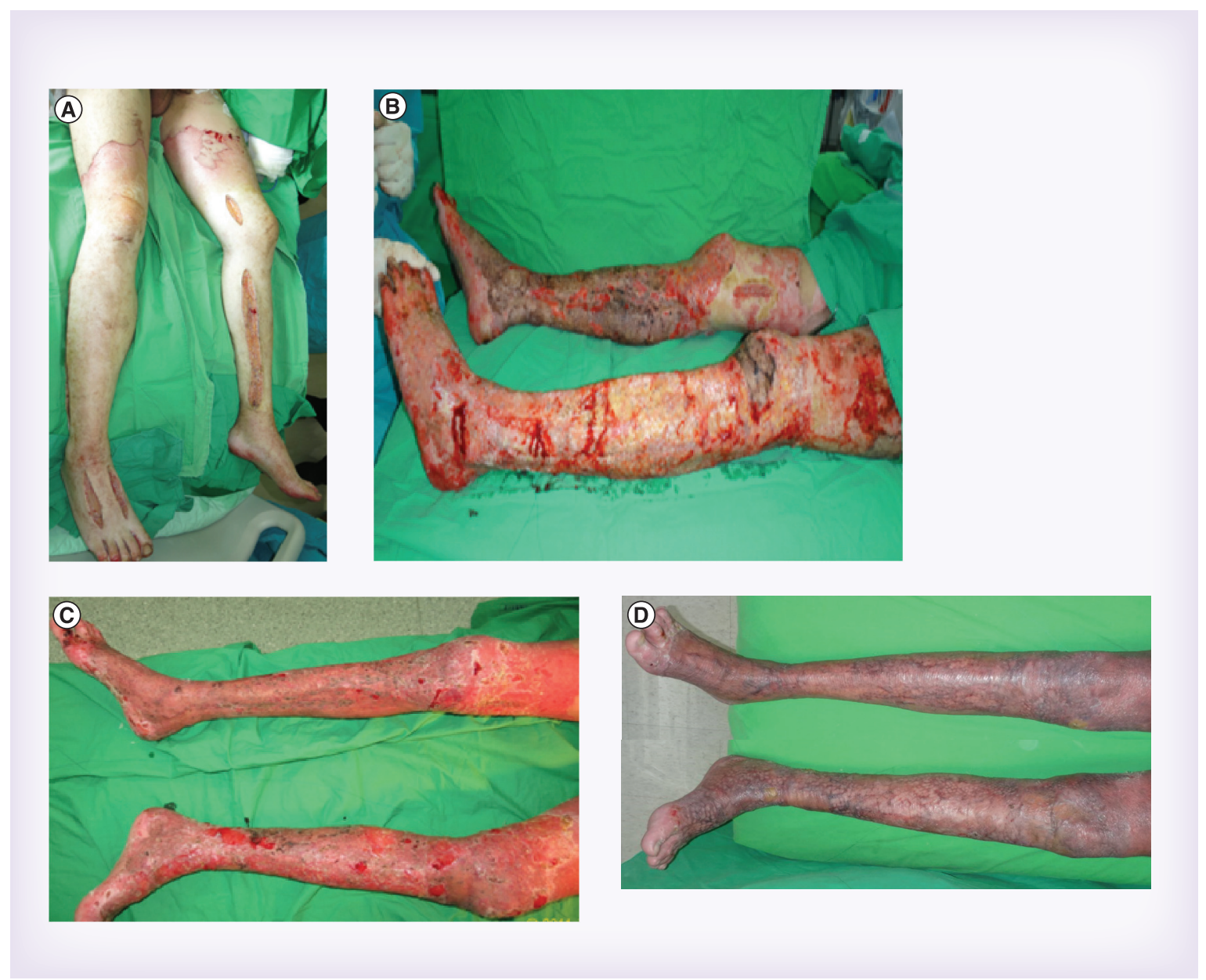

Figure 1. Left leg treated with MEEK (1:4), vacuum-assisted closure and regenerative epithelial suspension with ReCell ${ }^{\circledR}$. (A) before treatment, (B) at 2 weeks, (C) at 5.5 weeks and (D) at 2 months.

Overall, it proved effective for severe and moderate burn patients and the team plans to include $\mathrm{ReCell}^{\circledR}$ in combination with other treatment modalities at the Tri-Service General Hospital.

\section{Repair: burns \& trauma}

The compassionate use of $\mathrm{ReCell}^{\circledR}$ in treating major burns: a single-center experience

James H Holmes IV (Wake Forest University School of Medicine, USA) presented the keynote lecture in the Burns and Trauma section of the symposium. His experience with $\mathrm{ReCell}^{\circledR}$ dates to 2007 when the first clinical trial started in the USA. ReCell ${ }^{\circledR}$ is currently an investigational device in the USA and under clinical evaluation in preparation for application for regulatory approval. $\mathrm{ReCell}^{\circledR}$ is also available on a limited basis, through an investigational device exemption for compassionate use. In the Compassionate Use protocol developed by Holmes and colleagues, ReCell ${ }^{\circledR}$ is used to produce RES, which is sprayed over meshed splitthickness skin grafts with a minimum expansion ratio of 3:1. RES is also applied to donor sites and other areas of partial thickness burn injury. The populations treated include: adults with a TBSA of $40 \%$ or more and pediatrics with a 30\% TBSA threshold in older children, and as low as $20 \%$ in younger children with poor donor site options.

Holmes described the two-step procedure used in the Compassionate Use protocol. The first step involves complete excision of the dermis back to viable tissue. A dermal substitute, such as Integra ${ }^{\circledR}$ (Integra Lifesciences Corporation, NJ, USA) or PriMatrix ${ }^{\circledR}$ (TEI Medical, Inc., MA, USA), was applied as needed, or wounds were covered with a cadaveric allograft to prepare the injuries for autografting. The second procedure of epithelial autografting combined meshed splitskin autograft with RES to fill in the interstices. All donor sites were also treated with RES. Holmes noted they had not experienced any significant episodes of infection or graft loss using this protocol.

To date, the team has treated a total of 16 patients using this protocol, comprising ten adults and six children, all of whom were treated for burn wounds (case examples presented in Table 2). In the adult cohort 
Table 2. Case examples from the compassionate use of ReCell ${ }^{\circledR}$ in the USA.

\begin{tabular}{|llllllllll} 
Case & $\begin{array}{l}\text { Age } \\
\text { (years) }\end{array}$ & $\begin{array}{l}\text { TBSA } \\
(\%)\end{array}$ & $\begin{array}{l}\text { LOS } \\
\text { (days) }\end{array}$ & $\begin{array}{l}\text { LOS/TBSA } \\
(\%)\end{array}$ & $\begin{array}{l}\mathbf{C m}^{2} \text { at } \\
\text { excision }\end{array}$ & $\begin{array}{l}\mathbf{C m}^{2} \text { at } \\
\text { ReCell }^{\oplus} \# \mathbf{1}\end{array}$ & $\begin{array}{l}\mathbf{C m}^{2} \text { at } \\
\text { ReCell }^{\oplus} \# 2\end{array}$ & $\begin{array}{l}\mathbf{C m}^{2} \text { at } \\
\text { ReCell }^{\oplus} \text { \# }\end{array}$ & $\begin{array}{l}\text { Total } \\
\text { operations }\end{array}$ \\
\hline 1 & 19 & 75 & 98 & 1.31 & 11,625 & 4750 & 365 & None & 3 \\
\hline 3 & 39 & 63 & 61 & 0.97 & 13,439 & 7789 & 3250 & None & 3 \\
\hline
\end{tabular}

nine patients were treated. The mean age was 64 years with an average TBSA of $63 \%$. As a result of treatment, Holmes et al. were able to reduce mean length of stay (LOS) by approximately $50 \%$ compared with matched historical controls.

The children were treated with RES to minimize the large amount of donor skin required to treat their wounds. The mean age of the five remaining acute burn patients was 16 months, with an average 30\% TBSA. Since the treatment of children was new at the center they do not have matched historical controls but report reduced healing time with good scar outcomes, reduced mesh patterns and no contracture.

In summary, Holmes et al. found that the wounds consistently closed within 5-8 days and as a result, LOS has been reduced.

\section{Seven years of ReCell ${ }^{\circledR}$ at the Chelsea Burns Service}

The Chelsea Burns Service was one of the first centers in the UK to start using ReCell ${ }^{\circledR}$ in 2009, explained Isabel Jones (Chelsea and Westminster Hospital, UK). The Service has carried out 80-90 cases to date, which are almost exclusively burn wounds.

Jones presented a number of the cases who had presented to her department with mixed depth burn wounds on the face $(n=15)$, rest of body $(n=15)$ and pediatric patients with scalds $(n=6)$. The patients with facial burns ranged from 10 months to 54 years old, with TBSA of up to $40 \%$. The Chelsea Burns Service will use ReCell ${ }^{\circledR}$ to produce RES at between 1 and 23 days postinjury. In their opinion and based on clinical experience, the early use of $\mathrm{ReCell}^{\circledR}$ is appropriate, especially if they expect healing complications (scar, dyspigmentation) on the face.

Out of the 15 patients with facial burns, 12 healed within 4 weeks of the burn injury and treatment with RES with no permanent scarring. Three of the patients had deep dermal injury requiring additional reconstruction, but Jones used the cell suspension as an adjunct to promote healing.

Jones also presented data from 15 patients with mixed dermal burns on other areas of the body whose ages ranged from a few months to 60 years and with 4-90\% TBSA. RES produced using ReCell ${ }^{\circledR}$ was applied to the prepared wound bed between days 1 and 25 and in over half of the cases, the wounds healed without the requirement for further surgery. Jones discussed the specific case of a female patient in whom, at 2 weeks postinjury, healing was not progressing well. The team decided to apply split-thickness skin graft to the back of the patient's legs and then apply cell suspensions. One week after the procedure, the graft had taken and healing was proceeding normally.

Of particular note were the pediatric cases in which Jones has used ReCell ${ }^{\circledR}$. She presented the successful case of a 12-month-old baby who was treated with a combination of biological dressings (Biobrane ${ }^{\circledR}$, Smith and Nephew) and $\mathrm{ReCell}^{\circledR}$ within $24 \mathrm{~h}$ following a mixed depth scald injury. Additional procedures were not required and by 6 months she had healed remarkably well with minimal scarring of the skin. At 18 months postinjury, the site of the injury was no longer visible.

Jones also remarked on the use of RES on skin graft donor sites and risk of the development of a chronic wound (failure to heal after 6 weeks) at the donor site following surgery. Jones presented a number of cases of patients with burn donor sites that had failed to heal. The patients $(n=23)$, with an age range of 13-40 years, included eight young patients who had problems healing prior to the skin graft: eight healed in less than 2 weeks, nine in 13-40 days and there were a few outliers (one passed away, one did not heal at all and a few took more than 49 days to heal).

Jones asserted that ReCell ${ }^{\circledR}$ is a great adjunct to care, is easily combined with other treatment modalities and helped to optimize the outcomes she achieved in these patients.

\section{ReCell ${ }^{\circledR}$ - St Andrew's Burn Unit experience}

The St Andrew's center for Plastics and Burns (Chelmsford, UK) has successfully incorporated the $\mathrm{ReCell}^{\circledR}$ device into their standard practice and Ms Natalie Whybro presented a 3-year retrospective review of burn management practice with $\mathrm{ReCell}^{\circledR}$ at the Center. The data presented included a total of 100 patients with scalds and acute flame burns (Box 1). As part of the St Andrew's protocol RES is applied to the site of injury with meshed skin grafts and the donor site. Ms Whybro commented on the successful out- 
comes they have achieved, with limited scarring and complications. However, a full retrospective review was difficult due to incomplete records on many of these patients. The team at the center continues to incorporate the $\mathrm{ReCell}^{\circledast}$ device into their burns surgery and are participating in ongoing research into the effectiveness of the device.

\section{The use of ReCell ${ }^{\oplus}$ on the burned child}

Elvira Conti (Hospital A. Trousseau, France) specializes in the use of $\mathrm{ReCell}^{\circledR}$ in pediatric burns to the face and to children with darker colored skin. She discussed 35 cases of pediatric burn treatments combining RES into her standard of care. Her patients are mostly aged between 3 months and 15 years presenting with deep second- and third-degree burns with less than 10\% TBSA (Table 3).

\section{Long-term outcomes of ReCell ${ }^{\circledR}$ in pediatric partial thickness scalds}

It is estimated that there are 250,000 burn injuries annually in UK [5], a third of which occur in children, with scalds attributable to $65 \%$ of these injuries $[5,6]$. The aim of the retrospective study of 100 consecutive partial thickness pediatric scalds by the Pinderfields team and presented by Elliott Cochrane (Yorkshire and Humber Deanery, UK) was to examine the incidence of scar complications (e.g., keloid and hypertrophic scarring, itching, dyspigmentation) following a number of different treatments and combinations.

The average size of burns seen was $5 \%$, usually affecting the upper limbs or chest, and of varying depth. Five treatment modalities were used and included standard dressings, biological dressings $\left(\right.$ Biobrane $^{\circledR}$ ), split-thickness skin grafts, ReCell ${ }^{\circledR}$ and Biobrane ${ }^{\circledR}$ plus $\mathrm{ReCell}^{\circledR}: 39$ patients had dressings only; 22 were treated with Biobrane ${ }^{\circledR} ; 26$ had split-thickness skin grafting; nine patients had a combination of Biobrane ${ }^{\circledR}$ and $\mathrm{ReCell}^{\circledR}$; four patients received ReCell ${ }^{\circledR}$ alone.

Cochrane discussed the impact of severity and depth of the burn on the treatment modality used. Of note was the success the team has achieved with the use of biological dressings on partial thickness scalds. The team achieved healing, avoiding further surgical intervention when children were treated with Biobrane $^{\circledR}$; however, over $50 \%$ reported scarring and dyspigmentation. When biological dressings were applied over RES, this drops to only $25 \%$ of patients reporting scarring and dyspigmentation. In addition, a reduction in itch was also noted.

These data sets are currently undergoing statistical analysis pending publication and $\mathrm{ReCell}^{\circledR}$ remains part of the pediatric burns protocol at Pinderfields Hospital (West Yorkshire, UK).

\section{ReCell ${ }^{\circledast}$ utilization with skin substitutes} \& broadening therapeutic options

Alex Murray (Stoke Mandeville Hospital, UK) presented her team's approach to using dermal substitutes in combination with RES produced by the ReCell ${ }^{\circledR}$ device in major burns and complex soft tissue loss, and how therapeutic options can be broadened in these techniques.

In major burns initial wound scrub, escharotomy and full wound excision is currently the gold standard approach, but preparing the wound bed with negative-pressure wound therapy (NPWT) can minimize edema and maximize dermal substitute take. The wounds were prepared using scrubbing and excision with Versajet ${ }^{\circledR}$ (Smith and Nephew) and the dermal substitute (Integra) was applied. NPWT was used to improve vascularization prior to the application of a widely meshed, thinly harvested 3:1 graft in combination with RES to the vascularized dermal substitute recipient bed and all donor sites to reduce the risk of donor site morbidity.

Murray discussed the case of a 22-year-old male who sustained a 70\% TBSA burn injury. Full excision was performed immediately to prepare the wound bed, dermal substitute applied and edema was managed using NPWT. Neovascularization of the dermis was seen at 3 weeks, at which point a widely meshed autograft (3:1 except for the forearms and hands, 1.5:1) in combination with RES was applied. RES was also applied to donor sites and Murray remarked that all the donor sites she treated were healed by 3 weeks. In the case Murray presented, and representative of the patients she treated, the patient was $95 \%$ healed by 55 days, equating to 0.79 days healing per percentage TBSA. At 2 years post-treatment, the patient is active, has had two small surgical releases and also received $\mathrm{CO}_{2}$ laser treatment to improve scarring.

Box 1. Data gathered as part of St Andrew's Burn Unit review.

\section{Demographics}

- Total 100 patients, aged 9 months to 75 years

- Caucasian 57\%, African 26\%, south Asian 15\%, mixed race $2 \%$

- Median $17.5 \%$ TBSA

Mode of injury

- Adults - acute flame burns

- Children - scalds

Site of injury

- Facial (24), trunk (41) and upper limb (35)

Treatment modalities

- ReCell ${ }^{\circledR}$ and Biobrane ${ }^{\circledR}$

- ReCell ${ }^{\circledR}$ and meshed autografts

- ReCell ${ }^{\circledast}$ for donor sites

TBSA: Total burn surface area. 
Table 3. Case examples on the use of $\mathrm{ReCell}^{\circledR}$ on the burned child.

\begin{tabular}{|c|c|c|c|c|}
\hline Case number & Age & Gender & Injury & Treatment and results \\
\hline 1 & 6 years & $M$ & $\begin{array}{l}\text { Deep burns, } \\
16 \% \text { TBSA }\end{array}$ & $\begin{array}{l}\text { Following failure of skin graft, large mesh graft 6:1 } \\
\text { and ReCell }{ }^{\circledR} \text { was used. Reduced donor skin, good } \\
\text { skin pliability and pigmentation achieved }\end{array}$ \\
\hline 2 & 8 months & $\mathrm{F}$ & $\begin{array}{l}\text { Deep, extensive } \\
\text { scald, } 17 \% \text { TBSA }\end{array}$ & $\begin{array}{l}\text { Following excision and temporary cover a large } \\
\text { mesh graft and ReCell }{ }^{\circledR} \text { were applied to the } \\
\text { buttocks. Reduced donor skin requirement and } \\
\text { reduction in mesh pattern following healing }\end{array}$ \\
\hline 3 & 11 months & M & $\begin{array}{l}\text { Deep burn from } \\
\text { an overhot bath }\end{array}$ & $\begin{array}{l}\text { Extrusion plus infrared lamp for } 10-15 \text { days, large } \\
\text { mesh graft and suspension using ReCell }{ }^{\circledR} \text {. After } \\
4 \text { months a good flexibility of the skin had returned }\end{array}$ \\
\hline 4 & 7 years & M & $\begin{array}{l}\text { Burn with hot } \\
\text { metal }\end{array}$ & $\begin{array}{l}\text { High risk patient (hemophilia), large donor sites } \\
\text { contraindicated. Treatment was RES alone with a } \\
\text { small donor site (also treated with RES) and healed } \\
\text { by } 10 \text { days }\end{array}$ \\
\hline 5 & 9 months & $\mathrm{F}$ & Scalp burn & $\begin{array}{l}\text { Treated with RES alone to reduce donor skin } \\
\text { burden. After } 9 \text { months, news skin with limited } \\
\text { scarring and good pliability }\end{array}$ \\
\hline 6 & 12 years & M & $\begin{array}{l}\text { Scald burn to } \\
\text { the arm }\end{array}$ & $\begin{array}{l}\text { After } 7 \text { weeks failure to heal in dressings alone. } \\
\text { RES applied under local anesthesia and complete } \\
\text { healing achieved by } 20 \text { days }\end{array}$ \\
\hline
\end{tabular}

Murray believes that patients with complex soft tissue loss could benefit from this technique by optimizing wound closure using $\mathrm{ReCell}^{\circledR}$. It is, however, important to give time for multiorgan failure and sepsis to subside, allowing adequate demarcation of the level of tissue to be lost, followed by staged excision of necrotic tissue and amputation where necessary. Skin substitutes underneath NPWT, the meticulous preparation of the neodermis and vigilant microbiological cover are essential. Only then is the wound ready for the mesh autograft in combination with RES approach.

\section{Restart: chronic wounds}

Pilot randomized controlled trial on ReCell ${ }^{\circledR}$ for the treatment of venous leg ulcers

In his keynote lecture for the Chronic Wounds section of the Symposium, Paul Hayes (Addenbrooke's Hospital, UK) presented data from a pilot prospective randomized controlled trial to evaluate the effectiveness of ReGenerCellTM in combination with compression therapy for the treatment of venous leg ulcers (VLU). Hayes estimates that in vascular surgery departments, patients with VLU consume $10-20 \%$ of clinic time. VLU occur in approximately $1 \%$ of the US population [7], but this is increasing owing to an aging population and an increasing incidence of obesity [8]. By 80 years, the incidence is approximately $8 \%$. In VLU the skin breaks down and does not heal as a result of insufficient venous return. Hayes explained that VLU are slow to repair and even when treated with compression therapy, some wounds fail to heal within 24 weeks $[9,10]$. The patients experience pain, swelling, itching, discharge and recurrent infection. In turn this has a significant impact on QoL. The aim of this pilot study was to treat VLU failing compression therapy with RES produced by ReGenerCell ${ }^{\mathrm{TM}}$. Hayes is hopeful that treatment with RES ReGenerCell ${ }^{\mathrm{TM}}$ can turn such wounds around - it offers a clear economic impact for health services and has an important impact on patients.

Hayes described the study design, which included 52 patients with VLU across seven centers in Europe. Patients meeting the inclusion criteria entered a 2 -week run-in period to ensure consistent compression bandaging across sites and assess for rapid healing or infection. At the end of the run-in, eligible patients were randomized to receive treatment with RES in addition to compression therapy (active) or compression therapy alone (control). Patients were followed for 14 weeks, measuring wound size, wound images, pain and assessing QoL using the Charing Cross Venous Leg Ulcer quality of life questionnaire (CCVLUQ) [11]. For analysis the active and control groups were further stratified into small ulcers $\left(\leq 10 \mathrm{~cm}^{2}\right)$ and large ulcers $\left(>10 \mathrm{~cm}^{2}\right)$.

Patients enrolled on the study had an average age of 69 years. The median duration of the ulcers was 68 weeks; the average size of the small ulcers cohort 
was $5.8 \mathrm{~cm}^{2}$, the large ulcer cohort $22.8 \mathrm{~cm}^{2}$ (minimum $2.0 \mathrm{~cm}^{2}$, maximum $43.0 \mathrm{~cm}^{2}$ ). Most patients presented with comorbidities and these included well-controlled diabetes, peripheral arterial disease, arthritis and cardiovascular disease.

Hayes presented data that demonstrated some of the ulcers achieved $100 \%$ closure by 12 weeks; there was a positive trend toward wound closure but this did not reach statistical significance. However, positive changes in re-epithelialization were observed in RES-treated large ulcers by week 4, which reached statistical significance by week 14 ( $\mathrm{p}=0.01)$ (Figure 2).

In the small ulcers cohort effective healing on both the control and active groups was observed and Hayes remarked that this was not unexpected and most likely due to good compliance of the patients with their compression therapy for the duration of the study.

Of particular note Hayes felt the decrease in pain $(\mathrm{p}=0.017)$ the patients experienced within 2 weeks of treatment with RES was significant; a benefit not seen in the control groups (Figure 3). In addition, positive improvements in all the measured areas of the RES patients' QoL were observed, although the study was not powered to demonstrate significance in this measure.

Hayes summarized that the pilot study had demonstrated statistically significant improvements in wound size, pain and health-related QoL. Treatment with RES places wounds on a healing trajectory; this was of particular note in large ulcers $\left(>10 \mathrm{~cm}^{2}\right)$, which comprise the majority of VLU presenting clinically.

Strong results support progression to a pivotal trial, in which patients should be followed for 26 weeks rather than 14 weeks, and include a greater proportion of large ulcers. The study should also include a consistent method of wound bed preparation.

Hayes concluded that chronic VLU have a huge impact on the patient's QoL, as well as the economic burden to health services. In this study, autologous regenerative cell suspensions have shown a significant benefit for patients in terms of QoL and ulcer healing.

\section{The use of ReCell ${ }^{\circledast}$ in the treatment of complex foot wounds}

Harvey Chant (Royal Cornwall Hospitals Trust, UK) discussed his experience working with diabetic foot ulcers, most of which focuses on amputations for both minor and major indications. Complex foot wounds can be caused by a combination of factors, including trauma, ischemia, infection, renal failure and neuropathy. Diabetes is also a significant cause of complex foot wounds, with $15-25 \%$ of patients experiencing a diabetic foot ulcer in their lifetime [12]. These diabetic

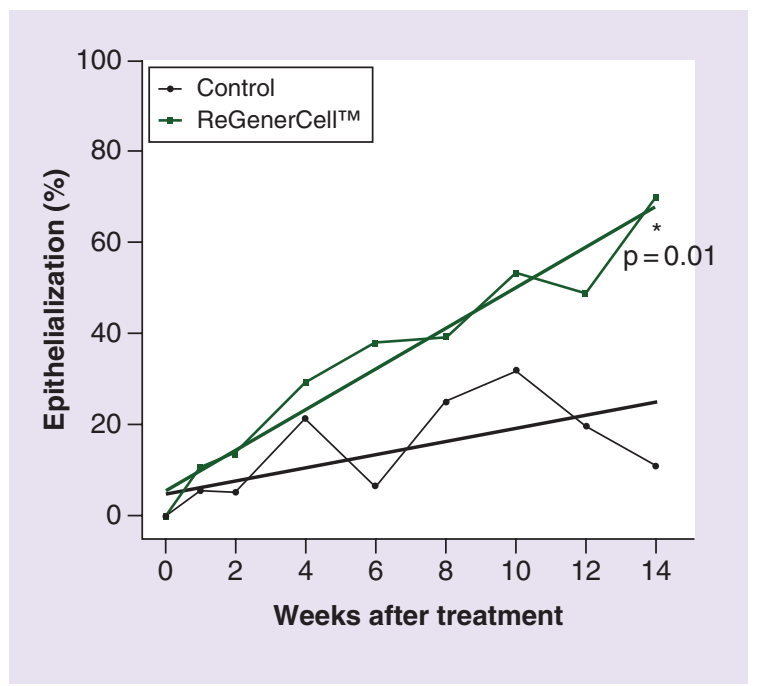

Figure 2. Re-epithelialization following treatment, large ulcers.

wounds often take months, if not years to heal, with significant impact to the patient and health service.

In this review of his experience of using ReGenerCell ${ }^{\mathrm{TM}}$ as part of his practice, Chant presented the cases of seven patients with diabetes who had complications arising from neuropathy and ischemia. The team treated the patients in the unit's podiatry clinic and used a combination of negative-pressure vacuum therapy to encourage granulation followed by RES produced using a small full-thickness skin sample from the same patient. Out of the patients presented, five healed completely with good quality skin forming over the wound. One of the patients developed vascular issues unrelated to the treatment of RES and required amputation of the affected limb. Chant described that one patient had received aggressive wound cleansing 1 week post-treatment by a health professional who was unaware the patient had received the ReGenerCell ${ }^{\mathrm{TM}}$ procedure. This patient failed to heal and Chant suggested that the inadvertent removal of the newly regenerating epithelium was the cause.

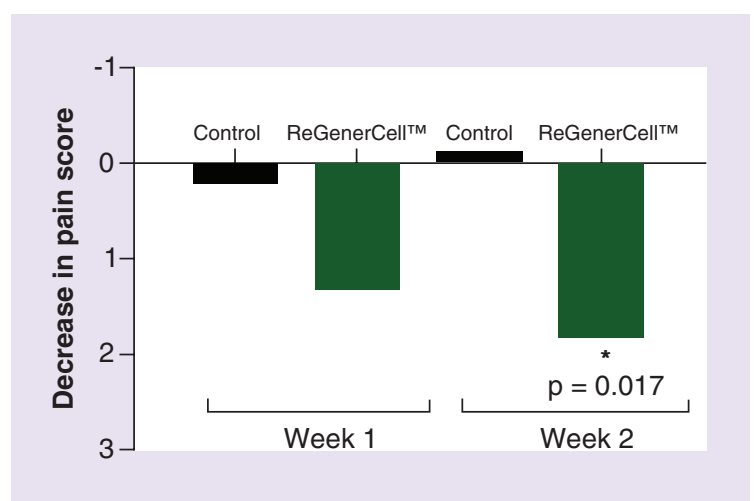

Figure 3. Decrease in pain after treatment. 
Chant also presented a complex foot wound that although not a diabetic foot wound, had many similarities and based on his previous experiences, led him to use ReGenerCell ${ }^{\mathrm{TM}}$ in this instance.

Chant presented the case history of a 62-year-old patient who had pneumococcal sepsis requiring high doses of inotropic and vasopressor agents. Her fingers were ischemic and feet necrotic. Her right foot was unsalvageable as a result of necrosis so a below-theknee amputation was carried out. Her left foot, however, had a healthy, intact fat pad, meaning the foot could be saved (although toes were removed). The patient was given one treatment of ReGenerCell ${ }^{\mathrm{TM}}$ followed by $\mathrm{Telfa}^{\circledR}$ Clear covered with saline-soaked gauze in dressings to create a tension bandage. At 4 weeks post-treatment, the foot was beginning to heal, and at 8 weeks epithelialization could be seen. At 19 weeks post-treatment her foot was healed, but standing not achievable. Chant believes that once the achilles is extended she should be able to bear weight on the foot, so it was deemed a successful treatment for a patient in whom it would have been difficult to do a skin graft.

Chant concluded that in his experience ReGenerCell ${ }^{\mathrm{TM}}$ had resulted in limb salvage and is a useful, cost-effective therapy in difficult-to-treat patients with complex wounds and multiple comorbidities.

\section{Managing complex chronic wounds using multimodalities}

Echoing Chant's presentation, Jeremy Rawlins (Fiona Stanley Hospital, Australia) asserted that a multidisciplinary approach to chronic wounds is essential and drew on his experience of managing difficult wounds in both Australia and the UK. Understanding the wound, the patient, and the difficulties, the patient will have with that wound is key. Rawlins also explained that an understanding of what the patient expects from treatment should be the priority. No person wants to live with a chronic wound, but the impact of the treatment on QoL must be considered. Rawlins presented a number of cases including chronic wounds on the scalp, abdomen and lower limbs using a combination of treatments including negative-pressure vacuum therapy, hyperbaric oxygen and skin grafting techniques, all in combination with cell suspension produced from ReGenerCell ${ }^{\mathrm{TM}}$.

Rawlins presented the case of a patient with a chronic wound to the whole top of the scalp following a traumatic injury. The wound was of mixed depth, both full and partial thickness. The full-thickness injuries were treated with full-thickness skin graft. In an attempt to minimize donor skin and preserve dermis, the mixeddepth areas were treated with meshed split-thickness skin graft and RES.
Rawlins then described the application of ReGenerCell ${ }^{\mathrm{TM}}$ in postsurgical oncology patients. An elderly patient presented with an open chronic wound to his upper posterior thigh, which had developed following surgery and radiotherapy for sarcoma. As a result of this treatment and other comorbidities the patient was high risk for further general anesthesia, but both patient and clinician were keen to close the wound. The surgeon felt treatment with a meshed skin graft together with RES produced from ReGenerCell ${ }^{\mathrm{TM}}$, performed under regional anesthesia, was appropriate for the patient. The procedure was successful and the wound fully healed within 10 weeks.

Rawlins presented the case of a male patient with a large VLU that was unresponsive to compression therapy, but who was compliant and willing to participate in an intensive course of hyperbaric oxygen therapy. The wound was debrided and covered with widely meshed split-thickness skin (3:1), followed by RES. The patient responded well and complete healing of the ulcer and donor site was achieved by 8 weeks. The patient did not experience ulcer recurrence at this site [13].

A final case showed the treatment of a patient with complex wounds to both legs following a road traffic accident. The patient had undergone a series of repeated procedures over several months and was psychologically depressed, malnourished and anemic. On his left leg the patient had received a failed free flap followed by fasciocutaneous flap and skin grafts; in addition the bones were not knitting and he had considerable skin defects to both legs that were not healing. After discussion with the patient, Rawlins and his colleagues felt that, due to infection, the patient's best option was amputation of his left leg. However, the team was able to use skin from the amputation to mesh graft and produce RES to cover the skin defects on the right leg, successfully achieving wound closure while avoiding generating an additional donor site wound. After many months of treatment the patient is now mobilized and his mood improved considerably.

In summary, Rawlins stated much of his success is owing to good interdisciplinary teamwork, choosing the right treatments for the patient and regularly discussing the treatment with the patient to ensure the best possible outcomes in these often life-changing injuries.

\section{Use of autologous skin cell suspensions to heal complex chronic wounds}

Tomàs O'Neill (Leeds General Infirmary, UK) presented a case study of a patient with a very painful VLU. O'Neill explained that from the literature a trend of effectiveness of ReGenerCell ${ }^{\mathrm{TM}}$ in lower limb chronic wounds was emerging and led his team to use the device to treat an 81-year-old lady, a retired GP with an 
ischemic and chronic VLU on her right leg. The patient had been an inpatient and bedbound for months and suffered severe pain on dressing changes owing to the high volume of exudate. Even with opioid analgesia she found dressing changes distressing. The wound was colonized by Pseudomonas and the skin quality of the surrounding tissue was poor. Angioplasty effectively improved inflow but the ulcer remained static for 6-8 weeks. Despite compression bandaging there was no evidence that the wound had epithelialized. Debridement, dressage and honey larvae therapy were also unsuccessful. The patient, her family and the anesthetist felt a graft under general anesthesia was too high a risk. Therefore O'Neill and colleagues performed a limited debridement and wash to reduce bacterial load under diluted local anesthesia. A small $4 \mathrm{~cm}^{2}$ splitthickness skin graft was taken from her upper thigh and used to produce RES using the ReGenerCellTM device and applied to the wound (Figure 4).

Following treatment, the most notable difference was the immediate absence of any analgesia postoperatively for dressing changes and the patient reported a total level of comfort during each dressing change. The patient herself reported that the absence of pain during dressing changes made the single greatest positive impact on her life. Over the course of 3 months, the wound re-epithelialized and good quality skin formed. At 2 months post-treatment, the patient became less compliant with her dressings and compression, and a superficial infection occurred. However, after discussions with the surgeons and compliance with compression dressings the wound closed fully by 3 months post-treatment. She was also no longer bedbound and could walk independently with a stick. In this case and in accordance with the observations by other authors and the ReGenerCell ${ }^{\mathrm{TM}}$ VLU randomized controlled trial, treatment with RES reduced pain in the VLU and led to improvements in QoL.

\section{Effective nursing care of the ReCell ${ }^{\circledR}$ treated chronic wound patient}

Gail Curran (Addenbrooke's Hospital, UK) followed Hayes' presentation on the ReGenerCellTM randomized controlled trial by discussing the wound care regimens used during the study, which contributed to the effective healing and decrease in pain of the RES-treated patients. In the vascular outpatient clinic, patients in the control and treatment arms of the study had their ulcers irrigated with sterile saline and local anesthesia (to manage the pain) and scrubbed using sterile gauze to pinpoint bleeding. A full-thickness skin sample was taken from either the hip or abdomen, disaggregated using the ReGenerCell ${ }^{\mathrm{TM}}$ device and the resulting cell suspension applied to the prepared wound by dripping and capillary action under the $\mathrm{Telfa}^{\circledR}$ Clear dressing. The donor site was sutured and moist dressings applied. Finally, compression dressings were applied.

All patients returned 1 week post-treatment to have their outer dressings removed, taking extreme care not to disturb the wound bed. The ulcer was redressed with moist dressings and compression therapy. At 2 weeks post-treatment patients reported a decrease in pain; exudate decreased; and there were areas of (fragile) granulation and re-epithelialization. At 6 weeks posttreatment a noticeable change in the patients' healing trajectory was observed and wound sizes had decreased. A second treatment was considered for patients who had not healed by $40 \%$. At 10 weeks, depending on the original size of the wound, the majority of patients were on their way to wound closure. Dressing techniques remained the same and changes depended on wound size and exudate. At 14 weeks post-treatment, some patients had fully healed. The new skin was very fragile but the patients were compliant with compression therapy and wounds remained closed.

The usual healing time for VLU in compression is 24 weeks [9,10] and Curran remarked that many of the patients healed before this point. She stated that it is essential that blood flow is restored to the affected limb where possible and prior to any other treatments (including cell suspension), to heal the wound and avoid ulcer recurrence. In Curran's clinic, the VLU patients treated with cell suspensions saw significant decreases in wound size, and a decrease in pain and exudate with resultant improvements in QoL. However, she is clear that patient compliance is key to success, along with good follow-up care and regular dressing changes.

\section{Science \\ Lympho-epithelial interactions in wound healing: where cell state, cell signaling \& timing matters}

Day 2 of the symposium was opened with a keynote presentation from Dr Nik Georgopoulos (University of Huddersfield, UK). Dr Georgopoulos' research uses biological models to explore, at cellular and molecular levels, the underlying mechanisms of action of pharmaceuticals and medical devices in disorders such as chemotherapy-induced alopecia and defective wound healing. Much of Georgopoulos' work relates to understanding cell signaling and how cells grow, divide, move and specialize.

Skin is very complex tissue with various components, and a specific organization to allow it to perform certain functions. Cells express specific proteins, driven by cell location. Basal cells have different properties and express different proteins to those in the higher 

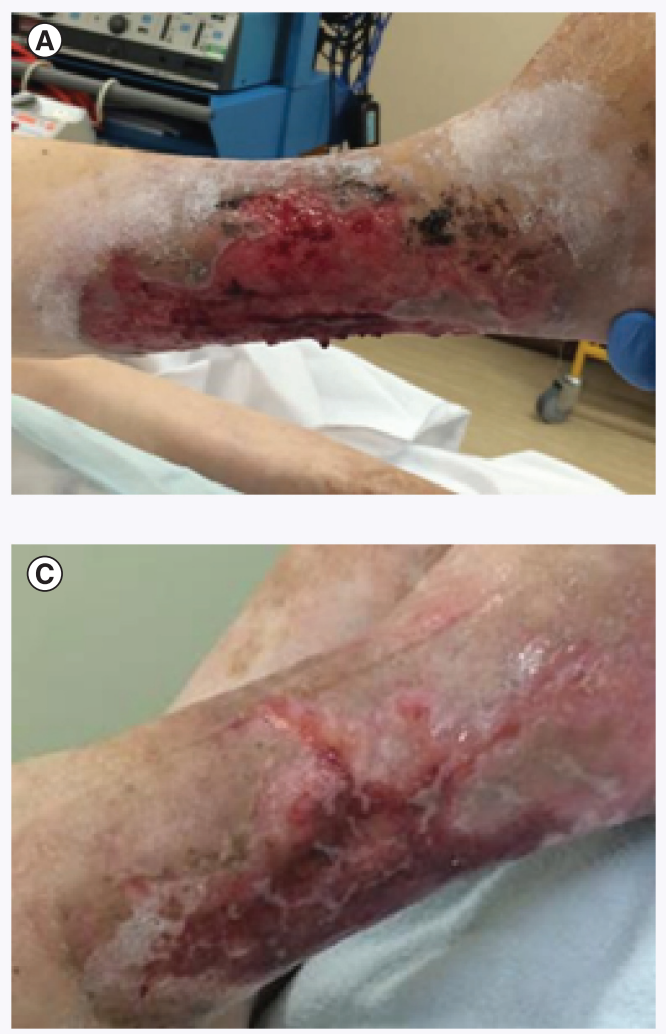
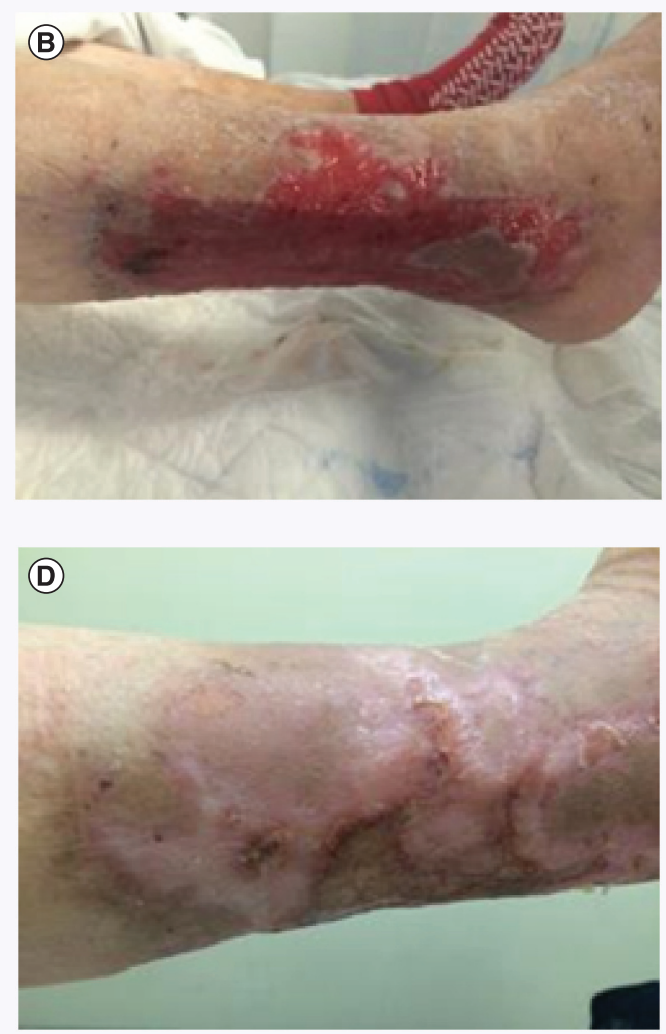

Figure 4. Regenerative epithelial suspension treatment using ReGenerCell ${ }^{\mathrm{TM}}$. (A) at baseline, (B) at day 7, (C) day 33 and (D) day 91.

layers of the skin. These cells rapidly divide and differentiate as they move through the epidermal layers, the protein signature changing as they do so. Georgopoulos explained he uses these proteins in his research on normal and defective healing.

Research into skin regeneration aims to understand more about the processes of wound healing, looks at ways to harness or enhance it and investigate why various treatments in some patients are ineffective. This in turn builds better therapies and informs the clinician about appropriate treatments for the patient. Georgopoulos explained that it is vital that the skin heals rapidly and from a survival perspective, we have evolved to close wounds quickly, which does not always have the best aesthetic result. Enoch and Leaper [14] explained the main stages of the process of wound healing - hemostasis, inflammatory, proliferation and remodeling stages - which overlap with each other. Everything is well orchestrated in the wound healing response, but when things go wrong they go very wrong. The presenters discuss treatments and methods to harness and enhance the stages to regener- ate good quality skin; however, sometimes the results are less than satisfactory. Research at the Skin Integrity Institute at Huddersfield aims to elucidate why and how wounds fail to heal and in which patients this might occur.

Cells are friendly entities that continuously talk to each other. During wound healing there are big changes at the cellular level; the cell needs to be fully reprogrammed. Some of the changes are similar to those seen during embryogenesis. Once inflammation is triggered the immune system aims to balance and control it, and the process is orchestrated to eventually close the wound and reform the intact barrier of the skin. In a chronic wound the process stalls; processes of re-epithelialization (cell migration and proliferation) become deranged. Proteins such as metalloproteases are secreted at the wrong time; fibroblasts become quiescent and senescent; and the skin lacks oxygen. This well-defined process is disrupted and the wound remains open and at risk of infection.

In the process of skin healing, the cells signal to other cells and also respond to such protein signals. 
This is interesting, since multiple pathways communicate to amplify response, activate and speed up the wound healing process. These signaling proteins drive activity, such as the Wnt pathway, which drives stem cell function and renewal, and reprograms differentiated cells to have stem cell-like properties to promote wound healing. These cells are differentiated to varying extents; they have to de-differentiate and they have to move by sliding on extracellular matrix (ECM), and are completely rewired at the transcriptional level - the genes and proteins expressed change. When it comes to how the cell communicates, there is a cascade of events in which a number of proteins will relay this message. Proteins become phosphorylated and these events allow them to relay the message sent to the nucleus transcription factors are activated and this allows the new expression of genes to promote healing. Specific proteins allow contact, but also tell the cells how to behave (move, stay put, divide).

Growth factors can be considered the driving force of wound healing, but their use as a monotherapy in the clinic has not worked well. The use of human serum (a soup of factors), however, helps keratinocytes but is detrimental to fibroblasts; human serum contacts TGF- $\beta 3$, which suppresses fibroblasts. HSP-90 can constitute up to $3 \%$ of a normal cell's protein content. This protein can be released during stress and released by specific cells to over-ride TGF- $\beta 3$. Therefore, it seems that HSP-90 could be the driving force of wound healing because factors released in the wound allow epithelization. HSP-90 starts to accumulate, reaches a threshold and overrides signals to allow the next stage to proceed.

Georgopoulos and his team have used the ReCell ${ }^{\circledast}$ process to investigate the cells and signals found in RES, including a number of the pathways discussed in the presentation. They have found RES exhibits a protein/signal profile expected in cells freed from contact inhibition, and in a proliferative and migratory state. They are continuing their research into how RES works with the goal of applying their findings to the clinical setting to aid the clinician in making an informed decision to select the right treatment for patients.

\section{Restore: plastics \& esthetics An experience using ReNovaCell ${ }^{\mathrm{TM}}$}

In the second keynote presentation of day 2, Jean Michel Rives (Clinique Esthetique Elysee Montaigne and Clinique Sainte Isabelle, France) presented his experience with ReNovaCell ${ }^{\mathrm{TM}}$, which has been available in France since 2006. The occipital scalp area has the highest concentrations of stem cells, keratinocytes and melanocytes. From this area, Rives takes a full- thickness sample, the length of which varies according to number of kits used. This area will generally heal quickly without hypertrophic scarring, and any surgical scarring will be hidden by hair regrowth. Rives often uses multiple devices to generate large amounts of concentrated cell suspension, which he feels results in a higher basal cell ratio. He has found that this improves the rate of healing and quality of results. Dr Rives prepares the patients' wounds using a classical surgical dermabrasion with a diamond burr. When treating hypertrophic scarring he uses more aggressive dermabrasion. Once Rives has applied the cell suspension he uses a biological dressing (Biobrane ${ }^{\circledR}$, Smith and Nephew), which he believes optimizes the wound environment for RES. This is then covered using conventional secondary dressings using two layers of sterile gauze. The first postoperative dressing change after ReNovaCell ${ }^{\mathrm{TM}}$ application is always done under the surgeon's supervision at 2-5 days postsurgery, depending on size and location. Biobrane $^{\circledR}$ is kept in situ. Vaseline gauze with topical HA (Laluset $^{\circledR}$, Genevrier) is applied on top of Biobrane ${ }^{\circledR}$. Following the initial twice weekly dressing change, patients are seen in the outpatient setting. Gradually the Biobrane ${ }^{\circledR}$ will unstick and should be tailored until it is completely healed. Laluset ${ }^{\circledR}$ is applied to the wound to reinforce skin quality and healing. Rives uses ReCell ${ }^{\circledR}$ for a number of indications, including vitiligo, hyperpigmentation, rhinophyma, facial acne sequelae and hypertrophic scarring. In future Rives also believes there could be an indication in cosmetic surgery for facial skin rejuvenation owing to stem cell potential.

Burns in particular, ReCell ${ }^{\circledR}$ presents a good opportunity for surgeons, and is a useful technique for quick and fast closure. It gives stable coverage even on infected areas, good functional outcomes and acceptable cosmetic results.

\section{Combination of needling \& ReCell ${ }^{\otimes}$ : a new promising approach}

Matthias Aust (Malteser Hospital, Germany) discussed the use of needling in combination with the cell suspension produced using the ReNovaCell ${ }^{\mathrm{TM}}$ device. With acute and chronic wounds there is an existing wound bed, but if it is a closed surface (intact skin) such as in vitiligo, hypertrophic scarring or photoaging, the skin must be prepared to provide a wound bed with pinpoint bleeding to receive the cells. When reviewing the literature, all techniques for the preparation of the wound bed work by removing the epidermis to varying degrees, and depth of this removal depends on the technique and the user. This carries risks such as dyspigmentation, scarring, delayed 
wound healing, prolonged downtime for the patient and potential infection of the open wound. Aust suggests that instead of removing the epidermis, such as using an ablative laser, the skin should be wounded to stimulate the body's own repair mechanisms and remodeling of matrix proteins. Aust uses a 3-mm needling device, which is rolled vertically, horizontally and diagonally across the surface of the scar creating microtrauma. In turn, this regenerates and thickens the epidermis [15]. However, needling alone does not achieve repigmentation, so Aust and colleagues tested the combination of needling and skin cell suspensions produced using ReNovaCell ${ }^{\mathrm{TM}}[16]$.

In total, 20 patients with a mean age of 33 years (6-60 years) with scars from deep second- and thirddegree burns have been treated. The average treated surface area was $94 \mathrm{~cm}^{2}\left(15-250 \mathrm{~cm}^{2}\right)$ and was focused on prominent areas such as the face, neck, chest and arms. The noncultured autologous skin cell suspension was produced using the ReNovaCell ${ }^{\mathrm{TM}}$ Autologous Cell Harvesting Device and applied to the scars, which had been prepared by microneedling as previously described. Control areas included microneedling only and a reference no treatment (microneedling or RES) in each patient. Aust followed the patients for 12 months postoperatively. Pigmentation changes were measured objectively using a Mexameter ${ }^{\circledR}$ (Courage + Khazaka electronic $\mathrm{GmbH}$ ) to quantify the presence of melanin in the skin at baseline, 3, 6, 9 and 12 months, together with assessments using the Patient and Observer Scar Assessment Scale.

Aust's data demonstrated significant repigmentation and improvements in skin quality in the areas of the hypertrophic scar receiving microneedling and RES. There were no improvements in pigmentation in the control areas. Only three of the patients failed to respond and Aust attributed this to less effective cleaning of the microneedled wound and serous fluid plugging of the needle channels.

Aust's results show a marked subjective and objective improvement in pigmentation. Both medical needling and RES preserve the epidermis, which results in a reduced risk of new scarring or dyspigmentation. Considering all factors, he concluded that the combination of medical needling and RES is a promising approach to repigment large hypopigmented burn scars.

ReCell ${ }^{\circledast}$ in vitiligo \& piebaldism patients: preliminary data of a randomized controlled study on the recipient site preparation Vitiligo is a common pigmentation skin disorder, with no discrimination between gender, ethnicity, skin type or where it appears on the body. Patients often find their disease distressing, especially when it occurs on visible areas such as the face, hands or legs. This can have a significant impact on QoL. Nonsegmented vitiligo is the most common type of the disease and is considered a progressive autoimmune disease. Segmented vitiligo is less common but usually more stable after the first depigmentation, and a good patient group when investigating new pigmentation techniques. Annelies Lommerts (The Netherlands Institute of Pigment Disorders) and colleagues undertook a study of the use of ReNovaCell ${ }^{\mathrm{TM}}$ in congenital segmented vitiligo of the lower legs, forehead and trunk. The patient-controlled prospective study ( $\mathrm{n}=10$ patients) was designed to investigate the effectiveness of RES in combination with ablative $\mathrm{CO}_{2}$ laser preparation techniques. Lommerts demonstrated the areas of depigmented skin that were treated with the ablative laser and RES repigmented (78\% of patients), while those treated with laser alone or untreated areas did not repigment (Figure 5) [17].

Lommerts also presented a preview of a newer study, which focuses on recipient site preparation. The team at The Netherlands Institute of Pigment Disorders is using RES in combination with fractional $\mathrm{CO}_{2}$ laser and a more superficial setting of $\mathrm{CO}_{2}$ laser, as well as repeating the deeper ablative $\mathrm{CO}_{2}$ treatment of the previous study. The hypothesis is that the fractional or more superficial settings may reduce patient discomfort during skin preparation and reduce risk of scarring while still achieving good repigmentation. As before, ten patients have received RES in combination with fractional, deep or superficial ablative $\mathrm{CO}_{2}$ laser settings, plus an untreated control area and are followed for 6 months and pigmentation assessed. Following wound bed preparation, RES was applied to each test area and to the donor sites. Following treatment, systemic antibiotics were prescribed for 1 week in addition to wound dressings, and UVA light was applied twice per week for 2-4 months postoperatively. To date all patients have been enrolled and are now being followed up for 6 months. The study has yet to complete, but results are promising. Of particular note is that in the patients who have completed so far, the superficial and deeper ablative laser methods with RES yield similar results; a very good repigmentation was seen in 60\% of patients and in fact, a number of the study patients have requested full treatment of their depigmented patches at the study end. The use of RES in combination with $\mathrm{CO}_{2}$ laser preparation at The Netherlands Institute of Pigment Disorders has been found to be an effective treatment for segmental vitiligo.

RES transplantation with the ReCell ${ }^{\oplus}$ device for vitiligo: the therapeutic protocol

The goal of any vitiligo treatment is to replace damaged melanocytes or replace those destroyed by dis- 

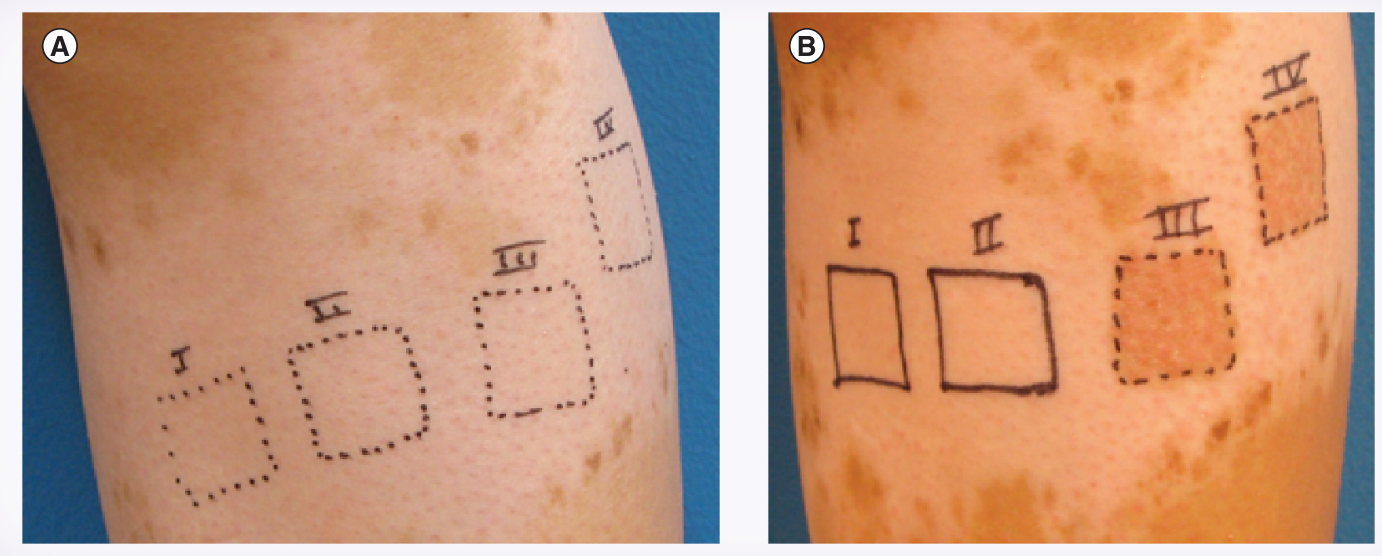

Figure 5. More than $75 \%$ repigmentation was seen in patients treated with ablative $\mathrm{CO}_{2}$ laser in combination with regenerative epithelial suspension. (A) before treatment and (B) after treatment.

I: fractional laser alone; II: Control group; III: $\mathrm{CO}_{2} 200 \mathrm{~mJ}$ plus regenerative epithelial suspension; IV: $\mathrm{CO}_{2} 150 \mathrm{~mJ}$ plus regenerative epithelial suspension.

ease. Topical therapies are often the first-line therapy, followed by phototherapy. Surgical intervention is the last resort, with two options available - transplantation or grafting. The usual ratio of donor site to transplant site is $1: 1$, so this can be a time-consuming treatment. Associate Professor Ang Zeng and Professor Zhifei Liu (both Peking Union Medical College Hospital, China) use cell suspensions produced using ReNovaCell ${ }^{\mathrm{TM}}$, and see it as an effective approach. They formed their own technical protocol and applied it as a treatment in a number of hospitals. The protocol comprised three actions: criteria for patient participation; the procedure; and postoperative management and follow-up to gather data. Inclusion criteria were no spreading of disease for at least 1 year, and a treatment area that is easy to mobilize and bandage. Optimal candidates had spotted repigmentation and a good response to blister therapy. Patients were also counseled on realistic expectations on the extent of pigmentation any treatment might restore, and so it was imperative that the patients understood that any improvement would be gradual. Patients also needed to comply with treatment. Other exclusion criteria were uncontrolled diabetes, smoking, pregnancy and keloid scarring. Before surgery, patients had a detailed consultation to provide treatment information and discuss medical history. Photographs were taken before treatment to track any changes. The procedure was performed in an outpatient clinic under local anesthesia. After cell treatment patients received UV phototherapy, which was monitored for hyperpigmentation.

Patients completed a questionnaire for patientreported outcomes, and the clinicians completed an assessment of adverse events and an esthetic evaluation.
After treating 100 patients the team feels they have an effective protocol incorporating ReNovaCell ${ }^{\mathrm{TM}}$ for the treatment of vitiligo, and this is now being used in a number of hospitals in China.

\section{ReCell ${ }^{\oplus}$ : an Australian case series}

Shobhan Manoharan (Brisbane Skin and Westside Dermatology, Australia) is a recent convert to the use of cell suspensions and has been using ReNovaCell ${ }^{\mathrm{TM}}$ in his clinic for the past 6 months. He described how he has incorporated ReNovaCell ${ }^{\mathrm{TM}}$ into his skin clinic and shared some preliminary results. He focused on hypopigmented scar treatment in combination with techniques including ablative and fractional laser. He has been using fractional lasers for a number of years, with topical hydroquinone and corticosteroids to reduce scarring. Fractional laser treatments have many benefits, including that they can be used in darker skin types, and cause less discomfort and downtime. In the three cases, he has completed with ReNovaCell ${ }^{\mathrm{TM}}$, he can already see improvements in scar quality and restoration of pigmentation. These are early days and the treated areas continue to improve. $\mathrm{He}$ will continue to monitor these patients for the next year and treat additional patients with a view to presenting his results in a peer-reviewed journal.

\section{Pretibial laceration treatment in the outpatient department with autologous noncultured cell therapy}

Pretibial lacerations are a significant injury to the aging population and account for approximately 50 in every 1000 attendances in the emergency department. There is currently no guidance on the management of these injuries in the UK. Robert Manton (St Mary's Hos- 
pital, London, UK) presented a case example of an 85-year-old with significant comorbidities, who was usually very independent and mobile. The patient presented acutely to the emergency department at King's College Hospital (London, UK) and was later admitted to the orthopedic team for formal wound debridement. The patient was seen by plastic surgeons at King's College Hospital, discharged and seen 1 week postoperatively. There was no evidence of granulation tissue at that time, so RES was applied following debridement under local anesthetic. The patient was discharged with a regular dressing and gauze. The team monitored the patient closely and by 3 weeks post-treatment, the wound area had decreased to $25 \%$, and $75 \%$ at 5 weeks. The wound was healed by 3 months without complication, good quality skin formed and her donor site healed without complication. Manton explained that they had found using RES in an outpatient setting advantageous to both patient and surgeon. The patient only required a local anesthetic, a small donor site and did not require hospital admittance. This enabled her to remain independent, mobile and with considerable cost savings to the National Health Service Trust. The team is now continuing to treat these injuries with RES and is gathering further data for publication.

\section{ReCell ${ }^{\circledast}$ surgical treatment for large area vitiligo}

Meng Zhongping (Borun Group, China) explained that vitiligo is common among the Chinese population, but there is a limited number of hospitals that specialize in treatment for the condition. The Borun Group is a specialized group of 23 hospitals focusing on the treatment of vitiligo, which was established in 2010, with more than 100 vitiligo experts employed. They have applied both traditional Chinese medicine and modern western medicine to treat the condition. They have been using ReNovaCell ${ }^{\mathrm{TM}}$ since 2014, and more than 50 patients have benefited from the treatment. There are three kinds of surgical therapies for vitiligo treatment - suction blister, particle pigmentation and ReNovaCell ${ }^{\mathrm{TM}}$ surgical treatments. Zhongping explained that the attraction of the ReNovaCell ${ }^{T M}$ procedure is its simplicity and that it can treat large areas of affected skin. As previously described, a protocol was developed by Professors Liu and Zeng, and this is now in use across the Borun Group Hospitals to make the ReNovaCell ${ }^{\mathrm{TM}}$ procedure available to the wider population.

\section{Peculiar scars that require multi-modalities}

The final presentation of the symposium was presented by Jeremy Rawlins in which he discussed staged scar revision. Rawlins discussed his 'tool-box' of procedures and how he has incorporated ReNovaCell ${ }^{\mathrm{TM}}$ into his practice as an adjunct to treatments to improve scar quality and pigmentation.

Of particular note was the work Rawlins has completed for rhinophyma. Rhinophyma can be difficult to treat as the patient is often left with a raw wound on the nose for many weeks. Rawlins supports using

\section{Executive summary}

- Skin is highly regenerative, but when damaged can cause significant harm to the patient. In fact, research has found that burn victims can be impacted the most.

- The use of ReCell ${ }^{\circledast}$ has been successful in treating burn victims with more that $40 \%$ total burn surface area as demonstrated by Hung-Hui Liu, initiating twice daily dressing changes and a modified Parkland fluid resuscitation protocol.

- In the Compassionate Use protocol developed by Holmes and colleagues, ReCell囚 is used to produce regenerative epithelial suspension (RES), which is sprayed over meshed split-thickness skin grafts with a minimum expansion ratio of 3:1.

- Jones presented a number of the cases who had presented to her department with mixed depth burn wounds on the face, and out of the total number of patients, 12 of them healed within 4 weeks of the injury treated with RES.

- Venous leg ulcers are slow to repair even when treated with compression therapy and are less likely to heal completely. Patients with venous leg ulcers may experience pain, swelling, itching, discharge and infection. Using RES produced by ReGenerCell ${ }^{\mathrm{TM}}$, patients with venous leg ulcers showed signs of improvement with wound closure.

- The use of ReGenerCell ${ }^{\mathrm{TM}}$ in diabetic foot ulcers in combination with negative-pressure vacuum, had shown to improvement and healed completely in five out of the six diabetic patients

- ReGenerCellTM has also been demonstrated in complex chronic wounds, including the scalp, very painful venous leg ulcers and ulcers.

- ReNovaCell ${ }^{\mathrm{TM}}$ has also been demonstrated in skin pigment disorders, where RES in combination with $\mathrm{CO}_{2}$ laser techniques showed improvement in pigmentation.

- Research into skin regeneration aims to understand more about the processes of wound healing, looks at ways to harness or enhance it and investigate why various treatments in some patients are ineffective. 
Versajet in this treatment modality as it allows the physician to reduce the amount of sebaceous tissue and keep the area clean. He then applied RES. Rawlins explained the wound re-epithelialized rapidly and good quality skin was formed, far superior than that achieved with standard scalpel excisions.

In patients presenting with significant scar tissue, Rawlins explained that it is essential to stimulate collagen and break up the scar. In a similar application to Aust's, Dermaroller and microneedling techniques in combination with ReNovaCell ${ }^{\mathrm{TM}}$ have been very effective to restore pigmentation to hypopigmented darker skin.

Management of patient expectations is extremely important and it is essential to include the patients in discussions to determine the best treatment modalities. Rawlins concluded that there is a diverse set of

\section{References}

1 Trim JE, Quick A. Regenerative epithelial suspension. Avita Medical (2015). www.ideal-ms.com/tag/regenerative

2 Duke J, Wood F, Semmens J et al. Rates of hospitalisations and mortality of older adults admitted with burn injuries in Western Australian from 1983 to 2008. Australas. J. Ageing 31(2), 83-89 (2012).

3 Graves C, Saffle J, Cochran A. Actual burn nutrition care practices: an update. J. Burn Care Res. 30(1), 77-82 (2009).

4 Lawrence A, Faraklas I, Watkins $\mathrm{H}$ et al. Colloid administration normalizes resuscitation ratio and ameliorates "fluid creep". J. Burn Care Res. 31(1), 40-47 (2010).

5 Hettiaratchy S, Dziewulski P. ABC of burns. Introduction. BMJ 328(7452), 1366-1368 (2004).

6 Barrow RE, Spies M, Barrow LN, Herndon DN. Influence of demographics and inhalation injury on burn mortality in children. Burns 30, 72-77 (2004).

7 Bergan JJ, Schmid-Schönbein GW, Smith PD, Nicolaides AN, Boisseau MR, Eklof B. Chronic venous disease. N. Engl. J. Med. 355(5), 488-498 (2006).

8 Moffatt CJ, Franks PJ, Doherty DC, Martin R, Blewett R, Ross F. Prevalence of leg ulceration in a London population. QJM 97(7), 431-437 (2004).

9 Heit JA. Venous thromboembolism epidemiology: implications for prevention and management. Semin. Thromb. Hemost. 28(Suppl. 2), 3-13 (2002).

10 Kurz N, Kahn SR, Abenhaim L et al. (eds.). VEINES Task Force Report: The management of chronic venous disorders of tools available for scar revision and that ReNovaCell ${ }^{\mathrm{TM}}$ presents a beneficial adjunct to treatment.

\section{Disclaimer}

The article was authored by an employee of Future Science Group. The opinions expressed herein reflect those of the author and are not the views of Future Science Group.

\section{Financial \& competing interests disclosure}

The author has no relevant affiliations or financial involvement with any organization or entity with a financial interest in or financial conflict with the subject matter or materials discussed in the manuscript. This includes employment, consultancies, honoraria, stock ownership or options, expert testimony, grants or patents received or pending, or royalties.

Writing assistance was provided by Avita Medical (Cambridge, UK).

the leg (CVDL): an evidence based report of an international task force. McGill University, Sir Mortimer B. Davis Jewish General Hospital, Montreal, Quebec, Canada (1995).

11 Smith JJ, Guest MG, Greenhalgh RM, Davies AH. Measuring the quality of life in patients with venous ulcers. J. Vasc. Surg. 31(4), 642-649 (2000).

12 NICE. Diabetic foot problems: prevention and management. (2015). www.nice.org.uk/guidance/ng19/chapter/Introduction

13 Jackson PC, Wilks D, Rawlins J, Matteucci PL. Combined use of hyperbaric oxygen and sprayed keratinocyte suspension to tackle a difficult wound. Ann. R Coll. Surg. Engl. 96(6), e20-e22 (2014).

14 Enoch S, Leaper D. Basic science of wound healing. J. Invest. Dermatol. 27, 514-525 (2007).

15 Aust MC, Fernandes D, Kolokythas P, Kaplan HM, Vogt PM. Percutaneous collagen induction therapy: an alternative treatment for scars, wrinkles, and skin laxity. Plast. Reconstr. Surg. 121(4), 1421-1429 (2008).

16 Busch KH, Bender R, Walezko N, Aziz H, Altintas MA, Aust MC. Combination of medical needling and noncultured autologous skin cell transplantation (ReNovaCell) for repigmentation of hypopigmented burn scars. Burns doi:10.1016/j.burns.2016.04.009 (2016) (Epub ahead of print).

17 Komen L, Vrijman C, Tjin EPM et al. Autologous cell suspension transplantation using a cell extraction device in segmental vitiligo and piebaldism patients: a randomized controlled pilot study. J. Am. Acad. Dermatol. 73(1), 170-172 (2015). 